\title{
Cardiometabolic Risk Factors among Healthcare Workers: A Cross-Sectional Study at the Sefwi-Wiawso Municipal Hospital, Ghana
}

\author{
James Osei-Yeboah $\mathbb{D}^{1},{ }^{1}$ Kenneth Kwame Kye-Amoah ${ }^{\mathbb{D}},^{2}$ \\ William K. B. A. Owiredu (iD), 3,4 Sylvester Yao Lokpo (iD), \\ Joseph Esson, ${ }^{2}$ Beatrice Bella Johnson, ${ }^{5}$ \\ Paul Amoah $(\mathbb{D}){ }^{6}$ and Romeo Asumbasiya Aduko ${ }^{1}{ }^{1}$ \\ ${ }^{1}$ Department of Medical Laboratory Sciences, School of Allied Health Sciences, University of Health and Allied Sciences, Ho, Ghana \\ ${ }^{2}$ Laboratory Department, Sefwi-Wiawso Municipal Hospital, Ghana Health Service, Sefwi-Wiawso, Western Region, Ghana \\ ${ }^{3}$ Department of Molecular Medicine, School of Medical Sciences, Kwame Nkrumah University of Science and Technology, \\ Kumasi, Ghana \\ ${ }^{4}$ Department of Clinical Biochemistry, Diagnostic Directorate, Komfo Anokye Teaching Hospital, Kumasi, Ghana \\ ${ }^{5}$ Department of Nursing, School of Nursing and Midwifery, University of Health and Allied Sciences, Ho, Ghana \\ ${ }^{6}$ Clinical Biochemistry Unit, Laboratory Department, Volta Regional Hospital, Ghana Health Service, Ho, Volta Region, Ghana
}

Correspondence should be addressed to James Osei-Yeboah; joyeboah@uhas.edu.gh

Received 31 July 2017; Revised 13 March 2018; Accepted 18 March 2018; Published 23 April 2018

Academic Editor: Abdelaziz M. Thabet

\begin{abstract}
Copyright (C) 2018 James Osei-Yeboah et al. This is an open access article distributed under the Creative Commons Attribution License, which permits unrestricted use, distribution, and reproduction in any medium, provided the original work is properly cited.
\end{abstract}

\begin{abstract}
Background. There is a dearth of information about the burden of cardiometabolic risk factors among the Ghanaian health workforce in the Western Region. This study sought to determine the prevalence of cardiometabolic risk factors among healthcare workers at the Sefwi-Wiawso Municipal Hospital in the Western Region of Ghana. Materials and Methods. A hospital-based cross-sectional study involving 112 employees of the Sefwi-Wiawso Municipal Hospital was conducted. The cardiometabolic risk variables assessed were obesity, hypertension, dyslipidaemia, and diabetes. Sociodemographic parameters were also captured. The prevalence of hypertension and obesity was determined using the JNC VII panel and WHO BMI criteria for obesity classifications. Blood lipids and glucose concentrations were evaluated using standard methods. Results. The prevalence of hypertension and prehypertension was $16.07 \%$ and $52.68 \%$, respectively. About $38.39 \%$ of participants were overweight, and $12.50 \%$ were obese. Atherogenic dyslipidaemia was $26.79 \%$, whereas prediabetes glycaemic levels and diabetes incidence were $5.41 \%$ and $4.50 \%$, respectively. Fifty percent $(50.00 \%)$ of participants presented at least one cardiometabolic risk factor. Aging and adiposity were associated with increasing cardiometabolic risk. Conclusion. Cardiometabolic risk factors are prevalent among healthcare providers in Sefwi-Wiawso. The cardiometabolic dysregulation observed among this cohort of healthcare professionals may be modulated by age and adiposity.
\end{abstract}

\section{Introduction}

Healthcare workers are an essential group of professionals whose work is critical to the maintenance of a healthy society [1]. Healthcare providers primarily comprise certified medical personnel who are mainly physicians, nursing staff, medical scientists, pharmacist, and medical technicians as well as nonclinical support staff including the administrative class [2]. Owing to their specialised training, healthcare professionals are expected to demonstrate a high knowledge and awareness regarding health consequences of lifestyle changes such as diabetes and cardiovascular diseases [3]. 
Considering the health-related knowledge at the disposal of hospital workers and their proximity to healthcare delivery, the assumption will be that the prevalence of cardiometabolic diseases and its modifiable risk factors would be relatively low $[1,4]$. However, certain work-related risk factors, such as shift work and mental and physical stress, which characterize the work environment of the hospital put health workers among a high occupational risk group for certain disease conditions [5].

Healthcare workers are mentors to the general population for a healthy life and have the principal responsibility of encouraging appropriate lifestyle changes that affect the prevention of these diseases [1,6]. Evidence suggests that there is a strong and consistent relationship between healthcare workers choices and the recommendations he or she makes to his or her patients [7]. Thus, preventing cardiovascular disease and other related metabolic risk factors among healthcare workers is a major strategy to achieving a healthy workforce in the workplace as well as in the general population [8].

Comprehensive information on the prevalence and character of cardiometabolic risk factors among healthcare professionals is essential to inform design and implementation of interventions to reduce cardiometabolic risk among healthcare workers [9]. To our knowledge, no work assessing the cardiometabolic risk profiles of Ghanaian healthcare workers in the Western Region has been conducted. In the light of this knowledge gap, the current study, therefore, sought to evaluate the prevalence of cardiometabolic risk factors among employees of the Sefwi-Wiawso Municipal Hospital in the Western Region of Ghana.

\section{Materials and Methods}

2.1. The Study Site. The Municipal Hospital serves as a referral facility for the various Health Centers, Communitybased Health Planning and Services (CHPS) compounds, and Clinics within the Sefwi-Wiawso Municipality and parts of the Sefwi Akontombra, Sefwi Juaboso, and Bibiani Anhwiaso Bekwai districts. The total bed capacity of the hospital is 94. The facility operates an outpatient department (OPD) with an average attendance of 150 clients per day. The OPD consists of an emergency unit with four beds, triaging area, antenatal clinic (ANC), antiretroviral (ART) clinic, tuberculosis (TB) clinic, pharmacy, laboratory including blood bank services, ear, nose and throat (ENT) clinic, dental clinic, and an eye clinic. The inpatients are managed in four wards, namely, children's ward, female ward, maternity ward, and males ward. At the time of this study, the staff strength stood at 224 employees including clinical and nonclinical staff.

2.2. Study Design and Study Population. This hospital-based cross-sectional study which involved 112 hospital employees participating in an annual medical screening program at the Sefwi-Wiawso Municipal Hospital in the period between 11 and 13 May 2016. The study included 48 male and 64 female participants between ages of 22 and 59 years.
2.3. Sample Size. Using the Raosoft online sample size calculator (http://www.raosoft.com/samplesize.html), the recommended minimum sample of 105 participants was calculated at $95 \%$ confidence level, $7 \%$ margin of error, and a response distribution of $50 \%$.

2.4. Blood Pressure (BP) Measurement. The blood pressure (BP) measurements were taken using the OMRON digital fully automated blood pressure monitor (OMRON Healthcare, IntelliSense BP785, HEM-7222). After participants had rested in a sitting position for at least ten minutes by qualified nurses, two measurements were taken with an appropriately sized cuff at a one-minute interval on the right arm, with the arm supported at heart level and feet flat on the floor [10]. The Seventh Report of the Joint National Committee on Prevention, Detection, Evaluation, and Treatment of High Blood Pressure (JNC VII) criteria for the classification of blood pressure was used. Normotensives were classified as systolic blood pressure (SBP) $<120 \mathrm{mmHg}$ and diastolic blood pressure $(\mathrm{DBP})<80 \mathrm{mmHg}$, prehypertension (SBP 120-129 mmHg or DBP $80-89 \mathrm{mmHg}$ ), hypertension stage 1 (SBP 140-159 mmHg or DBP 90-99 mmHg), and hypertension stage 2 ( $\mathrm{SBP} \geq 160 \mathrm{mmHg}$ or $\mathrm{DBP} \geq 100 \mathrm{mmHg}$ ) [11].

2.5. Anthropometric Measurement. A dual-purpose weight and height scale was used to measure body weight of participants to the nearest $0.1 \mathrm{~kg}$ and height to the nearest $0.1 \mathrm{~cm}$ with participants standing upright in a relaxed posture, heels together, feet slightly spread without shoes, and in light clothing (Health $\mathrm{O}$ meter ${ }^{\circledR}$ Professional 1049500 West 55th St. McCook, IL 60525-7110, USA). Body mass index (BMI) was calculated by dividing weight $(\mathrm{kg})$ by the square of the height in meters $\left(\mathrm{m}^{2}\right)$. Using the WHO classification of obesity, underweight was defined as BMI $<18.5 \mathrm{~kg} / \mathrm{m}^{2}$, overweight as $\mathrm{BMI} \geq 25.00 \mathrm{~kg} / \mathrm{m}^{2}$, obesity class I as BMI $30.00-34.99 \mathrm{~kg} / \mathrm{m}^{2}$, obesity class II as BMI $35.00-39.99 \mathrm{~kg} / \mathrm{m}^{2}$, and obesity class III as $\geq 40 \mathrm{~kg} / \mathrm{m}^{2}[12]$.

2.6. Biochemical Assays. Following an overnight fast, about $5 \mathrm{ml}$ venous blood sample was drawn from the antecubital vein between 7 a.m. and 10 a.m., of which 3 milliliters was dispensed into a vacutainer ${ }^{\circledR}$ serum separator tube using the closed vacutainer system and $2 \mathrm{ml}$ into fluoride oxalate tubes. Whole blood samples were centrifuged at $2500 \mathrm{rpm}$ for 5 minutes to obtain plasma, and serum after samples was allowed to clot. Using serum and plasma, the following biochemical assays were estimated: fasting blood glucose (FBG), total cholesterol (TC), triglyceride (TG), and high-density lipoprotein cholesterol (HDL-C). Very lowdensity lipoprotein cholesterol (VLDL-C) and Low-density lipoprotein cholesterol (LDL-C) were calculated using the Frederickson-Friedewald's formula where LDL-C = TC HDL-C - TG/2.2 [13]. The methods adopted for various assays were predetermined by the reagent manufacturer (ELITech Clinical Systems, SAS, Zone Industrielle-61500 SEES, France). All biochemistry assays were carried out at the Sefwi-Wiawso Municipal Hospital laboratory using 
TABLE 1: Haemodynamic, anthropometric, and dyslipidaemia atherogenic parameters of study population stratified by gender.

\begin{tabular}{lccc}
\hline Parameter & Total 112 (100) & Female 64 (57.14) & Male 48 (42.86) \\
\hline Age & $32.1 \pm 8.9$ & $32.3 \pm 9.9$ & $31.92 \pm 7.5$ \\
Age range & & & $25(52.08)$ \\
$22-30$ & $68(60.71)$ & $43(67.19)$ & $18(37.50)$ \\
$31-40$ & $29(25.89)$ & $11(17.19)$ & $3(6.25)$ \\
$41-50$ & $6(5.36)$ & $3(4.69)$ & $2(4.17)$ \\
51-59 & $9(8.04)$ & $7(10.94)$ & $118.3 \pm 11.7$ \\
SBP & $117.7 \pm 14.5$ & $117.2 \pm 16.4$ & $76.9 \pm 9.3$ \\
DBP & $76.7 \pm 9.8$ & $76.6 \pm 10.3$ & $23.9 \pm 3.3$ \\
BMI & $25.3 \pm 4.1$ & $26.4 \pm 4.4$ & $5.2 \pm 1.2$ \\
TCh & $5.4 \pm 1.1$ & $5.6 \pm 1.1$ & $0.9(0.4-3.8)$ \\
TG & $0.8(0.3-3.8)$ & $0.8(0.3-3.2)$ & 0.680 \\
VLDL & $0.4(0.2-1.7)$ & $0.4(0.2-1.4)$ & $0.4(0.2-1.7)$ \\
FBS & $4.7 \pm 1.2$ & $4.8 \pm 1.5$ & $4.6 \pm 0.7$ \\
\hline
\end{tabular}

Data are presented as mean \pm standard deviation, median (minimum-maximum) or frequency (percentage). SBP: systolic blood pressure, DBP: diastolic blood pressure, BMI: body mass index, TCh: total cholesterol, TG: triglyceride, VLDL: very low-density lipoprotein, and FBS: fasting blood sugar. $p$ is significant at 0.05 .

fully automated Selectra Pro S Chemistry autoanalyzer (Vital Scientific, B.V. Kanaalweg 24, Netherlands).

2.7. Ethical Consideration. Written approval for the study was sought and obtained from the management of SefwiWiawso Municipal Hospital. Participation was voluntary, and all participants consented to participate in the study. Analysis of the data was anonymous and nonlinked, and no participant names were used.

2.8. Statistical Analysis. All continuous variables were tested for normality using the Kolmogorov-Smirnov normality test with Lilliefors Significance Correction. Continuous parametric variables were expressed as a mean \pm standard deviation, and nonparametric variables were expressed as median (minimum and maximum). Categorical variables were expressed as frequencies and proportions. Comparisons of parameters were performed using unpaired $t$-tests, Mann-Whitney $U$ test, Chi-square $(\chi 2)$ tests, or Fisher exact tests where appropriate. A $p<0.05$ was considered as statistically significant for all analyses. IBM Statistical Package for the Social Sciences version 22.00 was used for data analysis (SPSS Inc., Chicago, USA; https://www.spss.com).

\section{Results}

The study involved 112 health workers with 64 (57.14\%) being female and the rest males 48 (42.86\%). The average age of the participants in this study was $32.1 \pm 8.9$ ranging from 22 years to 59 years with majority of 40 years and below (86.61\%). The male and female health workers statistically presented with comparable age $31.9 \pm 7.5(p=0.8462)$. The average systolic and diastolic blood pressure were 117.7 and $76.7 \mathrm{mmHg}$, respectively. The averaged body mass index of the female participant was $26.3 \mathrm{Kg} / \mathrm{m}^{2}$ and was significantly higher than that of the male participants $23.9 \mathrm{Kg} / \mathrm{m}^{2}$ ( $\left.p=0.0019\right)$. As seen from Table 1 , there was no gender variation among the study participants in the atherogenic and glycaemic variable measured. (See Table 1).

Using the JNC VII criteria for the classification of blood pressure, $18(16.07 \%)$ and 59 (52.68\%) of the health workers presented with hypertension and prehypertension, respectively. Among those presenting with hypertension, 15 $(83.33 \%)$ were classified as stage 1 and the remaining 3 $(16.67 \%)$ were in stage 2 . Also among the health workers classified as hypertensive, $8(44.44 \%)$ presented with both high systolic and diastolic blood pressure, 9 (50.00\%) presented with isolated high diastolic blood pressure, and 1 (5.56\%) presented with isolated high systolic blood pressure (See Table 2).

Using the WHO BMI classification for obesity, 2 (1.79\%) of the participants were classified as underweight, 43 (38.39\%) were overweight, and $14(12.50 \%)$ were obese. Among the obese participants, $78.57 \%$ were classified as class I and $21.43 \%$ as class II obesity. Obesity was significantly higher among the female health workers, 13 (20.31\%), than their male counterparts, 1 (2.08\%). Participants who presented with atherogenic dyslipidaemia were $18.75 \%$ with raised total cholesterol (TC), $10.74 \%$ with raised triglyceride (TG), and 3.57\% with raised very low-density lipoprotein (VLDL). Dyslipidaemia was comparable across gender. Five persons $(4.46 \%)$ had diabetes, and six $(5.36 \%)$ had prediabetic glycaemic levels. The difference in glycaemic levels did not significantly vary by gender (see Table 3 ).

Hypertension was found to be $33.33 \%$ among participants older than 40 years and estimate as between $13 \%$ and $14 \%$ among those below 40 years. Diabetes peaked among participants above 40 year to 50 year old. In general, high prevalence of obesity and dyslipaemia was observed among participants above 30 years (see Table 4 ).

A significant additive trend was observed between the mean atherogenic dyslipidaemia markers measured and adiposity grading. In all cases, the levels of atherogenic dyslipidaemia markers increased from underweight and peaked at 
TABLE 2: Prevalence of hypertension and haemodynamic presentation of health workers in Sefwi-Wiawso Municipal Hospital stratified by gender.

\begin{tabular}{|c|c|c|c|c|}
\hline Parameter & Total & Female & Male & $p$ value \\
\hline $\begin{array}{l}\text { Normal } \\
(\mathrm{SBP}<120 \text { and } \mathrm{DBP}<80)\end{array}$ & $35(31.25)$ & $21(32.81)$ & $14(29.17)$ & 0.0381 \\
\hline $\begin{array}{l}\text { Prehypertension } \\
\text { (SBP 120-139 or DBP 80-89) }\end{array}$ & $59(52.68)$ & $36(56.25)$ & $23(47.92)$ & \\
\hline $\begin{array}{l}\text { Stage } 1 \text { hypertension } \\
\text { (SBP 140-159 or DBP 90-99) }\end{array}$ & $15(13.40)$ & $4(6.25)$ & $11(22.90)$ & \\
\hline $\begin{array}{l}\text { Stage } 2 \text { hypertension } \\
(\mathrm{SBP} \geq 160 \text { or } \mathrm{DBP} \geq 100)\end{array}$ & $3(2.70)$ & $3(4.70)$ & $0(0.00)$ & \\
\hline $\begin{array}{l}\text { Hypertension } \\
(\mathrm{SBP} \geq 140 \text { or } \mathrm{DBP} \geq 90)\end{array}$ & $18(16.07)$ & $7(10.94)$ & $11(22.92)$ & 0.1191 \\
\hline $\begin{array}{l}\text { Hypertension with both } S B P \text { \& } D B P \\
(\mathrm{SBP} \geq 140 \text { and } \mathrm{DBP} \geq 90)\end{array}$ & $8(7.14)$ & $4(6.25)$ & $4(8.33)$ & 0.7227 \\
\hline $\begin{array}{l}\text { Hypertension with high SBP } \\
(\mathrm{SBP} \geq 140)\end{array}$ & $9(8.04)$ & $4(6.25)$ & $5(10.42)$ & 0.494 \\
\hline $\begin{array}{l}\text { Hypertension with high } D B P \\
(\mathrm{DBP} \geq 90)\end{array}$ & $17(15.18)$ & 7 (10.94) & $10(20.83)$ & 0.1197 \\
\hline $\begin{array}{l}\text { Hypertension with isolated SBP } \\
(\mathrm{SBP} \geq 140 \text { and } \mathrm{DBP}<90)\end{array}$ & $1(0.90)$ & $0(0.00)$ & $1(2.13)$ & 0.4234 \\
\hline $\begin{array}{l}\text { Hypertension with isolated DBP } \\
(\mathrm{SBP}<140 \text { and } \mathrm{DBP} \geq 90)\end{array}$ & $9(8.11)$ & $3(4.69)$ & $6(12.77)$ & 0.1645 \\
\hline
\end{tabular}

Data are presented as the frequency with the corresponding percentage in parenthesis. $p$ is significant at 0.05 . SBP: systolic blood pressure and DBP: diastolic blood pressure.

TABle 3: Prevalence of cardiometabolic risk factors among health workers in Sefwi-Wiawso Municipal Hospital stratified by gender.

\begin{tabular}{|c|c|c|c|c|}
\hline Parameter & Total & Female & Male & $p$ value \\
\hline Total respondent & $112(100)$ & $64(57.14)$ & $48(42.86)$ & \\
\hline \multicolumn{5}{|c|}{ Obesity classification } \\
\hline Underweight & $2(1.79)$ & $1(1.56)$ & $1(2.08)$ & \multirow[t]{5}{*}{0.0481} \\
\hline Normal & $53(47.32)$ & $25(39.06)$ & $28(58.33)$ & \\
\hline Overweight & $43(38.39)$ & $25(39.06)$ & $18(37.50)$ & \\
\hline Obesity class one & $11(9.82)$ & $10(15.63)$ & $1(2.08)$ & \\
\hline Obesity class two & $3(2.68)$ & $3(4.69)$ & $0(0.00)$ & \\
\hline Obesity & $14(12.50)$ & $13(20.31)$ & $1(2.08)$ & 0.0037 \\
\hline \multicolumn{5}{|l|}{ Atherogenic indices } \\
\hline Raised TCh & $21(18.75)$ & $12(18.75)$ & $9(18.75)$ & 1 \\
\hline Raised TG & $12(10.71)$ & $7(10.94)$ & $5(10.42)$ & 1 \\
\hline Raised VLDL & $4(3.57)$ & $3(4.69)$ & $1(2.03)$ & 0.6339 \\
\hline \multicolumn{5}{|l|}{ Atherogenic scores } \\
\hline None & $82(73.21)$ & $48(75.00)$ & $34(70.83)$ & \multirow[t]{4}{*}{0.3706} \\
\hline One & $25(22.32)$ & $12(18.75)$ & $13(27.08)$ & \\
\hline Two & $3(2.68)$ & $2(3.13)$ & $1(2.08)$ & \\
\hline Three & $2(1.79)$ & $2(3.13)$ & $0(0.00)$ & \\
\hline \multicolumn{5}{|c|}{ Glycaemia classification } \\
\hline Normoglycaemic & $101(90.18)$ & $58(90.63)$ & $43(89.58)$ & \multirow[t]{3}{*}{0.2925} \\
\hline Prediabetic & $6(5.36)$ & $2(3.13)$ & $4(8.51)$ & \\
\hline Diabetes & $5(4.46)$ & $4(6.25)$ & $1(2.08)$ & \\
\hline
\end{tabular}

Data are presented as the frequency with the corresponding percentage in parenthesis. $p$ is significant at 0.05 . TCh: total cholesterol, TG: triglyceride, VLDL: very low-density lipoprotein, and FBS: fasting blood sugar. 
TABLE 4: Age distribution of cardiovascular risks factors among health workers in Sefwi-Wiawso Municipal Hospital.

\begin{tabular}{lccc}
\hline Parameter & Frequency & Percentage & Rank \\
\hline Hypertension & & & \\
$22-30$ & 9 & 12.86 & $3 \mathrm{rd}$ \\
$31-40$ & 4 & 13.79 & $2 \mathrm{nd}$ \\
$41-50$ & 2 & 33.33 & $1 \mathrm{St}$ \\
$51-59$ & 3 & 33.33 & $1 \mathrm{St}$ \\
Diabetes & & & \\
$22-30$ & 2 & 2.86 & $3 \mathrm{rd}$ \\
$31-40$ & 0 & 0.00 & $4 \mathrm{th}$ \\
$41-50$ & 2 & 33.33 & $1 \mathrm{St}$ \\
$51-59$ & 1 & 11.11 & $2 \mathrm{nd}$ \\
Obesity & & & \\
$22-30$ & 5 & 7.14 & $4 \mathrm{th}$ \\
$31-40$ & 6 & 20.69 & $2 \mathrm{nd}$ \\
$41-50$ & 1 & 16.67 & $3 \mathrm{rd}$ \\
$51-59$ & 2 & 22.22 & $1 \mathrm{St}$ \\
Dyslipidaemia & & & \\
$22-30$ & 11 & 15.71 & $4 \mathrm{th}$ \\
$31-40$ & 11 & 37.93 & $1 S \mathrm{St}$ \\
$41-50$ & 1 & 16.67 & $3 \mathrm{rd}$ \\
$51-59$ & 2 & 22.22 & $2 \mathrm{nd}$ \\
\hline
\end{tabular}

Data is presented as frequency, percentage, and ranks.

overweight or obese (Figures 1(a), 1(b), and 1(c)). Glycaemia levels showed a significant trend across increasing adiposity grading, troughed among those graded as underweight and peaked among those graded as obese (Figure 1(d)) (see Figure 1).

In general, aging was associated with increasing blood pressure, glycaemia, and dyslipidaemia. Adiposity was positively correlated with glycaemic levels and dyslipidaemia. Increasing levels of glycaemia were associated with corresponding increases in systolic blood pressure and dyslipidaemia (see Table 5).

\section{Discussion}

The current study included 112 fairly young $(32.1 \pm 8.9$ years $)$ healthcare professionals employed at the Sefwi-Wiawso District Hospital in the Western Region of Ghana at the time of the study. The demographic characteristics of the study population (see Table 1) are comparable to reports of healthcare professionals in other facilities, Kadjebi Ghana [14] and Lagos Nigeria [15]. The similarities include age and gender distribution.

Using the WHO BMI classification for obesity, 43 (38.39\%) of the participants were overweight, and 14 (12.50\%) were obese. The reported burden of overweight and obesity among health care givers varies across various jurisdictions. At the Kadjebi District in the Volta Region of Ghana, a lower percentage of overweight $(25 \%)$ and a similar percentage of obesity (12.7\%) were recorded. [14]. Duodu et al. [16] observed that $31.8 \%$ of healthcare professional in the Hohoe
Municipal Hospital were overweight and 28.9\% were obese. Among a tertiary health institution in Accra, Aryeetey and Ansong [17] found that $43 \%$ of the employees were overweight and $13 \%$ were obese. In other African countries, overweight and obesity among healthcare employees ranged from 31.4 to $44.7 \%$ and 23.25 to $27.35 \%$ in Nigeria [ $4,15,18$ ], Skaal and Pengpid [19] reported $26.5 \%$ and $47 \%$ (overweight and obesity) in South Africa, and Ondicho et al. [9] reported $30.9 \%$ and $27.9 \%$ in Kenya.

Gender preponderance to obesity among the African population in general and healthcare employees is tilted toward females $[9,15,18]$. The suggested reasons for this phenomenon include the relatively sedentary lifestyle of African women, cultural appreciation of fatness as beauty, a sign of affluence and good living, and genetics [19, 20]. In concordance with earlier reports, the proportion of female healthcare workers, 13 (20.31\%), with obesity in the current study was significantly higher than their male counterparts, $1(2.08 \%)$. The burden of overweight and obesity is linked to noncommunicable diseases (NCDs) such as diabetes, hypertension, cardiovascular disorders, and cancers, all of which could increase morbidity and mortality [15, 21-23]. In the workplace, obesity is reportedly associated with weight discrimination, increased rates of absenteeism, presenteeism (health-related limitations at work), occupational injury, short-term disability, and reduced productivity [24-27]. Moreover, obesity is related to early retirement from the workplace, and this could lead to difficulty in retaining health workers whose numbers are already low in most developing countries [28].

In the current study, using the JNC VII criteria for the classification of blood pressure, 18 (16.07\%) and 59 (52.68\%) of the health workers presented with hypertension and prehypertension, respectively. Among those presenting with hypertension, 15 people representing $83.33 \%$ were classified as stage 1 , and the remaining $(16.67 \%)$ were in stage 2 . Additionally, among the hypertensive healthcare workers, $8(44.44 \%)$ presented with both high systolic and diastolic blood pressure, whereas $9(50.00 \%)$ presented with isolated high diastolic blood pressure and $1(5.56 \%)$ presented with isolated high systolic blood pressure (Table 2). The prevalence of hypertension $(16.07 \%)$ recorded in this study is higher than the $5.7 \%$ reported by Kasu et al. [14] and $14.1 \%$ by Duodu et al. [16] among Ghanaian healthcare givers. However, the rate is lower than the $17.5 \%$ to $37.5 \%$ recorded among health workers in a systematic review of hypertension prevalence in West Africa as well as the $34 \%$ prevalence reported among College of Health Sciences employees in a Ghanaian University [17, 29]. Moreover, prevalence rates higher than that of the current study have also been reported in Nigerians [30], Indians [3], and Europeans [5]. Of particular interest in the current study is the high rate of prehypertension observed among this apparently healthy Ghanaian health work professionals. Prehypertension may offer a window of opportunity to prevent established hypertension from developing; however, when left unmanaged, it could lead to increases in hypertension-related cardiovascular burden [31]. A previous report by Jardim et al. [32] in a prospective cohort study among a group of healthcare professionals observed an 


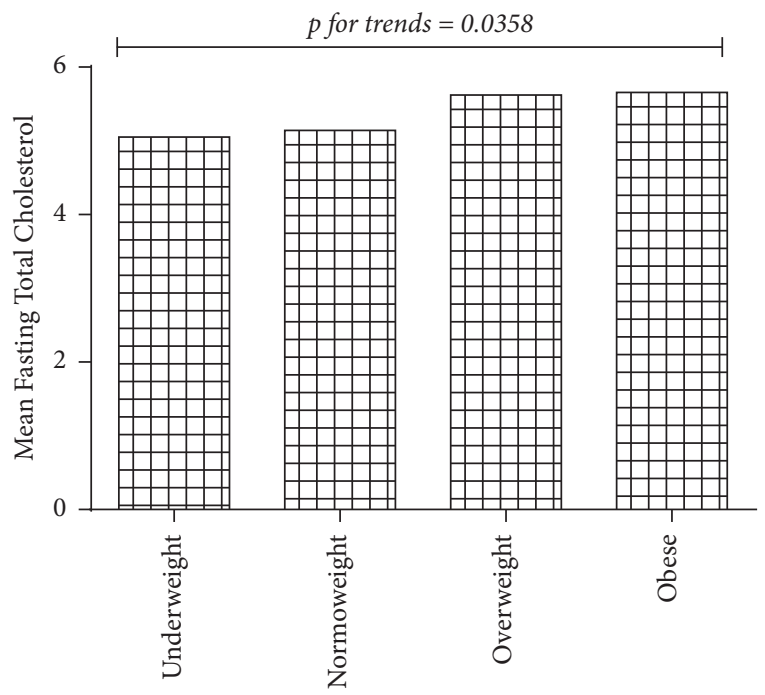

(a)

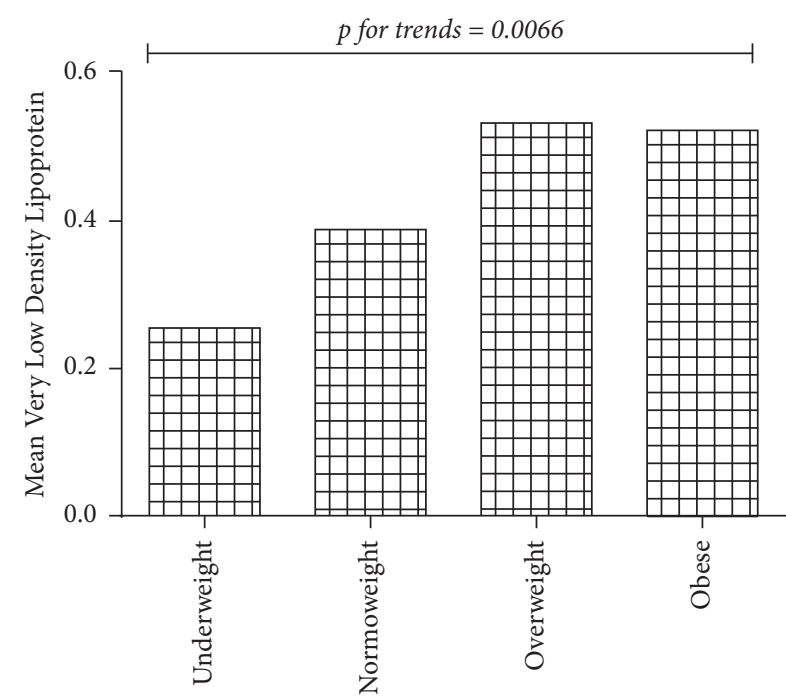

(c)

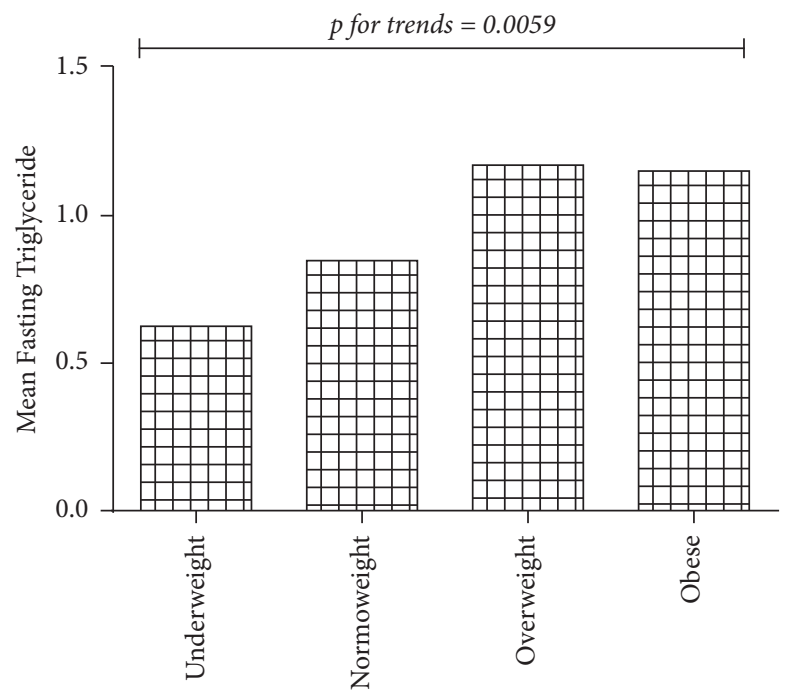

(b)

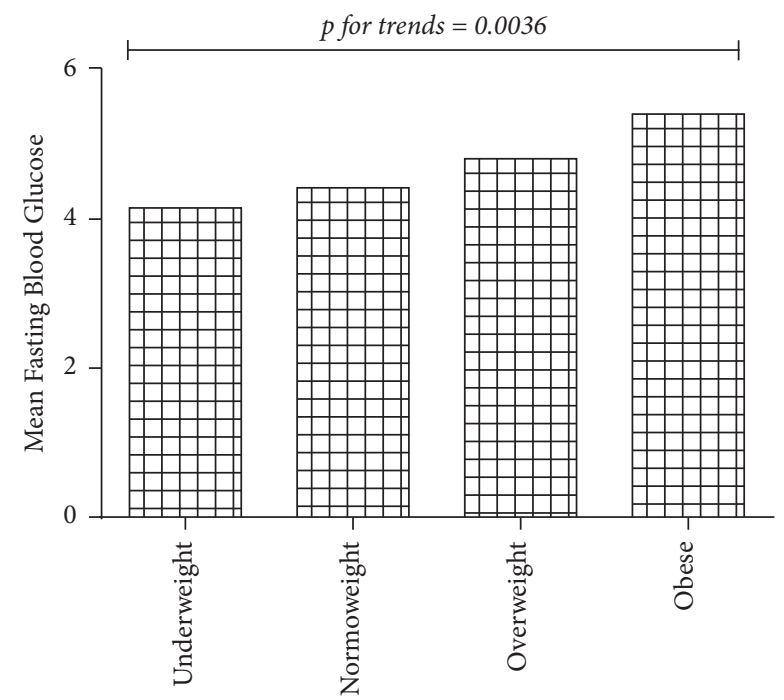

(d)

FIGURE 1: Association between adiposity, atherogenic indices, and glycaemia among health workers in Sefwi-Wiawso Municipal Hospital.

TABLE 5: Pearson bivariate correlation of cardiometabolic risk factors among hospital staff at Sefwi-Wiawso Municipal Hospital.

\begin{tabular}{lcccccc}
\hline Parameter & BMI & SBP & DBP & FBS & TCH & TG \\
\hline Age & 0.15 & $0.36^{* *}$ & $0.29^{* *}$ & $0.26^{* *}$ & -0.01 & $0.28^{* *}$ \\
BMI & & 0.17 & 0.16 & $0.21^{*}$ & $0.28^{* *}$ & $0.24^{*}$ \\
SBP & & $0.74^{* *}$ & $0.37^{* *}$ & 0.04 & $0.24^{* *}$ \\
DBP & & & 0.17 & 0.00 & 0.08 \\
FBS & & & & $0.19^{*}$ & 0.01 & $0.32^{* *}$ \\
TCH & & & & 0.00 \\
TG & & & & $0.28^{* *}$ & $0.27^{* *}$ \\
\hline
\end{tabular}

Data are presented as correlation coefficient of correlation. ${ }^{*} p$ is significant at $0.05,{ }^{* *} p$ is significant at 0.01 , BMI: body mass index, SBP: systolic blood pressure, DBP: diastolic blood pressure, FBS: fasting blood sugar, TCh: total cholesterol, TG: triglyceride, and VLDL: very low-density lipoprotein. 
increase in the prevalence of hypertension from $6.0 \%$ to $16.7 \%$ after 15 years of follow-up.

Disturbances in glucose and lipid metabolism are often contemporaneous and strongly linked to subsequent development of cardiovascular morbidity in a state of insulin resistance [33]. The prevalence of undiagnosed diabetes among the study population was $5(4.50 \%)$, and $6(5.41 \%)$ presented with prediabetic glycaemic levels. Thirty $(26.29 \%)$ of the healthcare providers presented with atherogenic dyslipidaemia, with $5(16.67 \%)$ of these participants presenting with multiple atherogenic lipid abnormalities. Significantly, all the employees with diabetes were clinical staff. Also a greater proportion of the clinical staff presented with raised TCh $(23.26 \%)$ levels compared to their nonclinical counterparts (3.85). Consistent with the findings of the current study, earlier investigators have reported the incidence of dyslipidaemia and disordered glucose metabolism among Asian healthcare providers [2, 3, 33].

We observed that an increasing level of glycaemia was associated with a corresponding increase in atherogenic lipid parameters (see Table 5). Though, not clearly understood, postulated mechanisms have linked glycaemic dysregulation and dyslipidaemia. In insulin-resistant states, there is upregulation of insulin levels, increased hepatic gluconeogenesis and glucose output, reduced suppression of lipolysis leading to a high free fatty acid influx, and increased hepatic VLDL secretion resulting in hypertriglyceridaemia and reduced plasma levels of HDL [34].

A significant additive trend was observed between the mean atherogenic dyslipidaemia markers and adiposity grading. In all cases, the levels of atherogenic dyslipidaemia markers increased from underweight and peaked at overweight or obese (Figures 1(a), 1(b), and 1(c)). Similarly, glycaemia levels showed a significant trend across increasing adiposity grading, troughing among those graded as underweight, and peaking among those graded as obese (Figure $1(\mathrm{~d})$ ). Though the precise mechanisms are still unclear, accumulating evidence indicates that obesity is closely associated with an increased risk of metabolic diseases such as insulin resistance, type 2 diabetes, and dyslipidaemia [35]. Evidence suggests that chronic inflammation in the adipose tissue may play a critical role in the development of obesity-related metabolic dysfunction [36].

Aging has been demonstrated to be a significant determinant for the development of morbid heart conditions and insulin resistance states leading to type 2 diabetes [37, 38]. Though in the current study increasing age was found to associate with most cardiometabolic parameters assessed (see Table 5), the age stratification of cardiometabolic risk factors revealed a relatively high levels of hypertension $(13 \%$ to $14 \%$ ), obesity ( $7 \%$ to $21 \%$ ), and dyslipidaemia (16\% to $38 \%$ ) among respondents 40 years and younger (see Table 4). Among black populations, relatively early onset of cardiovascular abnormalities has been reported [39-41]. Owusu et al. [42] postulated the critical age threshold of 39 years for hypertension among a Ghanaian population. Though genetic predisposition to this phenomenon has been suggested, there is a consensus that this is modulated by environmental factors $[43,44]$. The main attributed factor for the surge in cardiometabolic diseases in the Ghanaian population is urbanization, which is accompanied with lifestyle modifications such as diet change, physical inactivity, stress, and risk behaviours (smoking, alcohol consumption, etc.) [42, 45, 46].

The hypothesis that, armed with the knowledge of the prevention of cardiometabolic risk factors, healthcare workers were expected to present lesser prevalence of risk factors to the general population did not hold in this study, since 56 $(50.0 \%)$ of this study population presented with at least one of the cardiometabolic risk factors assessed (obesity, dyslipidaemia, hypertension, and diabetes), 47 (42.0\%) presented with one risk factor, $8(7.1 \%)$ presented with two risk factors, and $1(0.9 \%)$ presented with four cardiometabolic risk factors.

\section{Conclusion}

Cardiometabolic risk factors are prevalent among healthcare providers in Sefwi-Wiawso Municipal Hospital. The cardiometabolic dysregulation observed among this cohort of healthcare professionals may be modulated by age and adiposity. Lifestyle measures to reduce the burden of cardiometabolic risk factors should be encouraged among this group of professionals.

\section{Conflicts of Interest}

Authors have declared that no competing interests exist.

\section{Authors' Contributions}

This work was carried out with collaboration between all authors. All authors have reviewed and approved the final manuscript for submission.

\section{Acknowledgments}

The authors are grateful to the management and the staff of the Sefwi-Wiawso Municipal Hospital for their participation in this study.

\section{References}

[1] S. Sharma, T. Anand, J. Kishore, B. Dey, and G. Ingle, "Prevalence of modifiable and non-modifiable risk factors and lifestyle disorders among health care professionals," Astrocyte, vol. 1, no. 3, pp. 178-185, 2014.

[2] C.-M. Lin and C.-Y. Li, "Prevalence of cardiovascular risk factors in Taiwanese healthcare workers," Industrial Health, vol. 47, no. 4, pp. 411-418, 2009.

[3] A. Ramachandran, C. Snehalatha, A. Yamuna, and N. Murugesan, "High prevalence of cardiometabolic risk factors among young physicians in India," Journal of the Association of Physicians of India, vol. 56, pp. 17-20, 2008.

[4] O. G. Egbi, S. Rotifa, and J. Jumbo, "Prevalence of hypertension and its correlates among employees of a tertiary hospital in Yenagoa, Nigeria," Annals of African Medicine, vol. 14, no. 1, pp. 8-17, 2015.

[5] E. Sovova, M. Nakladalová, M. Kaletova, M. Sovova, L. Radova, and M. Kribska, "Which health professionals are most at risk for cardiovascular disease? or do not be a manager," International 
Journal of Occupational Medicine and Environmental Health, vol. 27, no. 1, pp. 71-77, 2014.

[6] M. Nobahar and M. R. Razavi, "Lifestyle and the Most Important Risk Factors of Cardiovascular Disease in Physicians, Nurses, and Faculty Members," Middle East Journal of Rehabilitation and Health, vol. 2, no. 2, 2015.

[7] S. K. B. Hegde, S. Sathiyanarayanan, S. Venkateshwaran, A. Sasankh, P. Ganeshkumar, and R. Balaji, "Prevalence of Diabetes, Hypertension and Obesity among Doctors and Nurses in a Medical College Hospital in Tamil Nadu, India," world, vol. 1, 4 pages, 2015.

[8] A. A. Akintunde, A. A. Salawu, and O. G. Opadijo, "Prevalence of traditional cardiovascular risk factors among staff of Ladoke Akintola University of Technology, Ogbomoso, Nigeria," Nigerian Journal of Clinical Practice, vol. 17, no. 6, pp. 750-755, 2014.

[9] Z. Ondicho, D. Omondi, and A. Onyango, "Prevalence and socio-demographic factors associated with overweight and obesity among healthcare workers in Kisumu East Sub-County, Kenya," American Journal of Medicine and Medical Sciences, vol. 6, no. 3, pp. 66-72, 2016.

[10] D. Lemogoum, Y. K. Seedat, A. F. B. Mabadeje et al., "Recommendations for prevention, diagnosis and management of hypertension and cardiovascular risk factors in sub-Saharan Africa," Journal of Hypertension, vol. 21, no. 11, pp. 1993-2000, 2003.

[11] A. V. Chobanian, G. L. Bakris, H. R. Black et al., "The seventh report of the joint national committee on prevention, detection, evaluation, and treatment of high blood pressure: the JNC 7 report," The Journal of the American Medical Association, vol. 289, no. 19, pp. 2560-2572, 2003.

[12] WHO, Obesity: preventing and managing the global epidemic, World Health Organization, Geneva, Switzerland, 2000.

[13] W. T. Friedewald, R. I. Levy, and D. S. Fredrickson, "Estimation of the concentration of low-density lipoprotein cholesterol in plasma, without use of the preparative ultracentrifuge," Clinical Chemistry, vol. 18, no. 6, pp. 499-502, 1972.

[14] E. S. Kasu, A. Ayim, and J. Tampouri, "Prevalence of obesity among health workers in Kadjebi District of Ghana," biology agriculture and healthcare, vol. 5, 2015.

[15] S. O. Iwuala, O. O. Ayankogbe, F. A. Olatona et al., "Obesity among health service providers in nigeria: Danger to long term health worker retention?" Pan African Medical Journal, vol. 22, article no. 1, 2015.

[16] C. Duodu, T. K. Awuni, P. Attito, and F. B. Zotor, "Assessment of Overweight and Obesity Prevalence Among Practicing Nurses and Midwives in the Hohoe Municipality of the Volta Region, Ghana," Science Journal of Public Health, vol. 3, no. 6, pp. 842851, 2015.

[17] R. Aryeetey and J. Ansong, "Overweight and hypertension among college of health sciences employees in Ghana," African Journal of Food, Agriculture, Nutrition and Development, vol. 11, no. 6, 2011.

[18] M. Dankyau, J. Shu'aibu, A. Oyebanji, and O. Mamven, "Prevalence and correlates of obesity and overweight in healthcare workers at a tertiary hospital," Journal of Medicine in the Tropics, vol. 18, no. 2, pp. 55-59, 2016.

[19] L. Skaal and S. Pengpid, "Obesity and health problems among South African healthcare workers: Do healthcare workers take care of themselves?" South African Family Practice, vol. 53, no. 6, pp. 563-567, 2011.

[20] K. Nsiah, V. Shang, K. Boateng, and F. Mensah, "Prevalence of metabolic syndrome in type 2 diabetes mellitus patients,"
International Journal of Applied and Basic Medical Research, vol. 5, no. 2, p. 133, 2015.

[21] O. Funke and K. S. Ibrahim, "Blood pressure and body mass index among Jos University Teaching Hospital staff," Transnational Journal of Science and Technology, vol. 3, pp. 73-83, 2013.

[22] S. Pam, K. Dakok, N. Chagok, U. Sirisena, E. Taddy, and E. Gadong, "Body mass index (BMI) and waist to height ratio (WHTR) for prediction of cardiovascular diseases: Women at higher risk than men in Jos," Advances in Life Science and Technology, vol. 33, 2015.

[23] B. Adeboye, G. Bermano, and C. Rolland, "Obesity and its health impact in Africa: a systematic review," Cardiovascular Journal of Africa, vol. 23, no. 9, pp. 512-521, 2012.

[24] S. B. Harvey, N. Glozier, O. Carlton et al., "Obesity and sickness absence: Results from the CHAP study," Occupational Medicine , vol. 60, no. 5, pp. 362-368, 2010.

[25] D. M. Gates, P. Succop, B. J. Brehm, G. L. Gillespie, and B. D. Sommers, "Obesity and presenteeism: the impact of body mass index on workplace productivity," Journal of Occupational and Environmental Medicine, vol. 50, no. 1, pp. 39-45, 2008.

[26] M. Moreau, F. Valente, R. Mak et al., "Obesity, body fat distribution and incidence of sick leave in the Belgian workforce: The Belstress study," International Journal of Obesity, vol. 28, no. 4, pp. 574-582, 2004.

[27] P. Capodaglio, G. Castelnuovo, A. Brunani, L. Vismara, V. Villa, and E. Maria Capodaglio, "Functional limitations and occupational issues in obesity: A review," International Journal of Occupational Safety and Ergonomics, vol. 16, no. 4, pp. 507$523,2010$.

[28] D. K. Houston, J. Cai, and J. Stevens, "Overweight and obesity in young and middle age and early retirement: The ARIC study," Obesity, vol. 17, no. 1, pp. 143-149, 2009.

[29] W. K. Bosu, "The prevalence, awareness, and control of hypertension among workers in West Africa: a systematic review," Global Health Action, vol. 8, Article ID 26227, 2015.

[30] A. O. Owolabi, M. O. Owolabi, A. D. OlaOlorun, and I. O. Amole, "Hypertension prevalence and awareness among a health workforce in Nigeria," Internet Journal of Medical Update-EJOURNAL, vol. 10, no. 2, pp. 10-19, 2015.

[31] A. M. Adeoye, A. Adebiyi, M. O. Owolabi, D. T. Lackland, G. Ogedegbe, and B. O. Tayo, "Sex Disparity in Blood Pressure Levels Among Nigerian Health Workers," The Journal of Clinical Hypertension, vol. 18, no. 7, pp. 685-689, 2016.

[32] T. D. S. V. Jardim, P. C. B. V. Jardim, W. E. C. De Araújo, L. M. S. S. Jardim, and C. M. Salgado, "Cardiovascular risk factors in a cohort of healthcare professionals - 15 Years of evolution," Arquivos Brasileiros de Cardiologia, vol. 95, no. 3, pp. 332-338, 2010.

[33] E. Al-nuqali, B. A. Abaalkhail, and K. M. Alshareef, "Prevalence of dyslipidemia and its associated factors among employees of primary health care centers, Jeddah, Saudi Arabia," International Journal, vol. 5, no. 5, p. 946, 2016.

[34] R. K. Avramoglu, H. Basciano, and K. Adeli, "Lipid and lipoprotein dysregulation in insulin resistant states," Clinica Chimica Acta, vol. 368, no. 1-2, pp. 1-19, 2006.

[35] U. J. Jung and M. S. Choi, "Obesity and its metabolic complications: the role of adipokines and the relationship between obesity, inflammation, insulin resistance, dyslipidemia and nonalcoholic fatty liver disease," International Journal of Molecular Sciences, vol. 15, no. 4, pp. 6184-6223, 2014. 
[36] C. N. Lumeng and A. R. Saltiel, "Inflammatory links between obesity and metabolic disease," The Journal of Clinical Investigation, vol. 121, no. 6, pp. 2111-2117, 2011.

[37] S. Tsirona, F. Katsaros, A. Bargiota, S. A. Polyzos, G. Arapoglou, and G. N. Koukoulis, "Prevalence and determinants of type 2 diabetes mellitus in a Greek adult population," Hormones, vol. 15, no. 1, pp. 88-98, 2016.

[38] S. H. Nyarko, "Prevalence and Sociodemographic Determinants of Hypertension History among Women in Reproductive Age in Ghana," International Journal of Hypertension, vol. 2016, Article ID 3292938, 2016.

[39] A. Akosa and H. Armah, "Cardiomegaly in Ghana: An autopsy study," Ghana medical journal, vol. 39, no. 4, p. 122, 2005.

[40] O. S. Ogah, "Cardiomegaly in Ghana: An autopsy study," Ghana Medical Journal, vol. 43, no. 2, p. 93, 2009.

[41] W. K. Bosu, "Epidemic of hypertension in Ghana: a systematic review," BMC Public Health, vol. 10, article 418, 2010.

[42] I. K. Owusu, C. Aryee, W. K. Owiredu, J. Osei-Yeboah, E. Owusu-Dabo, and E. Laing, "Analysis of atherogenic and anthropometric profiles of normotensive and hypertensive ghanaians in the kumasi metropolis," British Journal of medicine and Medical Research, vol. 7, no. 5, pp. 378-397, 2015.

[43] P. Poirier, "Obesity, adiposity indices, and blood pressure; ethnicity does matter," American Journal of Hypertension, vol. 21, no. 3, p. 244, 2008.

[44] T. A. Kotchen, C. E. Grim, J. M. Kotchen et al., "Altered relationship of blood pressure to adiposity in hypertension," American Journal of Hypertension, vol. 21, no. 3, pp. 284-289, 2008.

[45] R. Ofori-Asenso and D. Garcia, "Cardiovascular diseases in Ghana within the context of globalization," Cardiovascular Diagnosis and Therapy, vol. 6, no. 1, pp. 67-77, 2016.

[46] N. Kodaman, M. C. Aldrich, R. Sobota et al., "Cardiovascular disease risk factors in Ghana during the rural-to-urban transition: A cross-sectional study," PLoS ONE, vol. 11, no. 10, Article ID e0162753, 2016. 


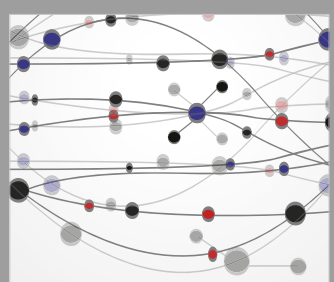

The Scientific World Journal
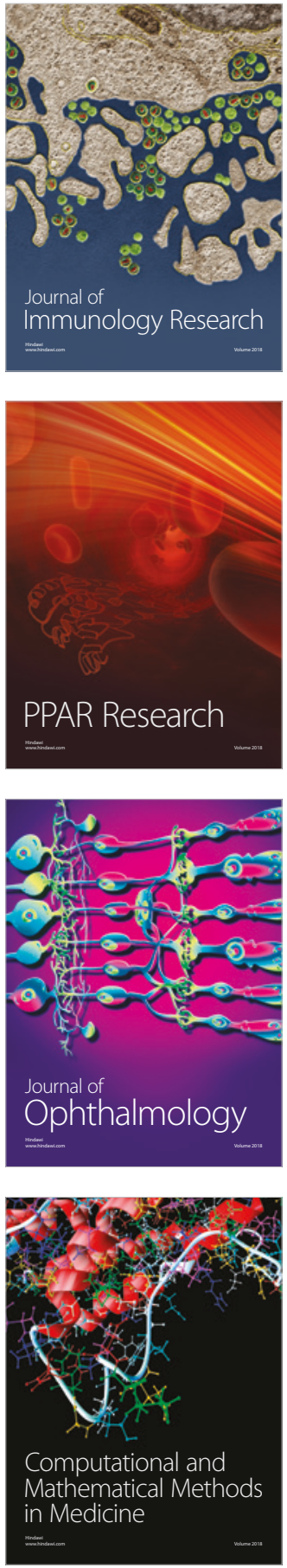

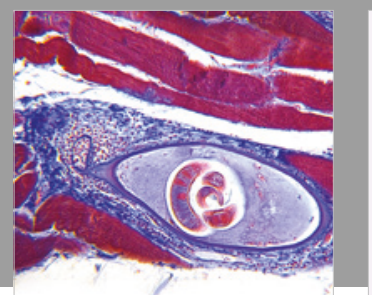

Gastroenterology Research and Practice

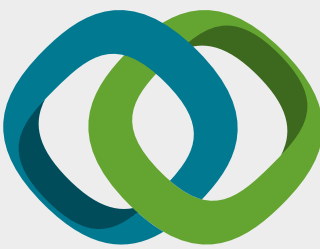

\section{Hindawi}

Submit your manuscripts at

www.hindawi.com
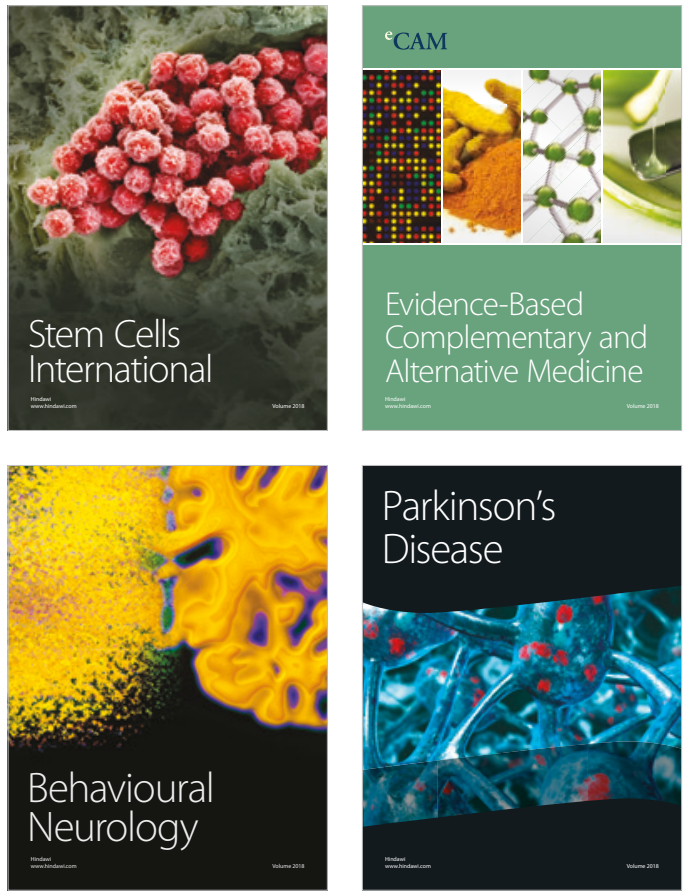

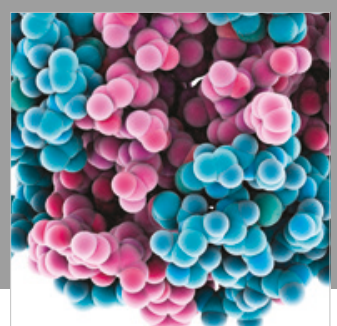

ournal of

Diabetes Research

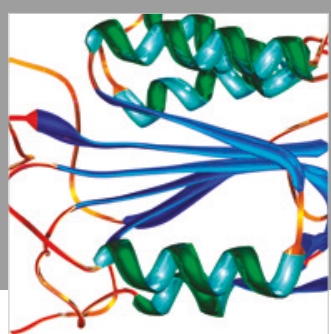

Disease Markers
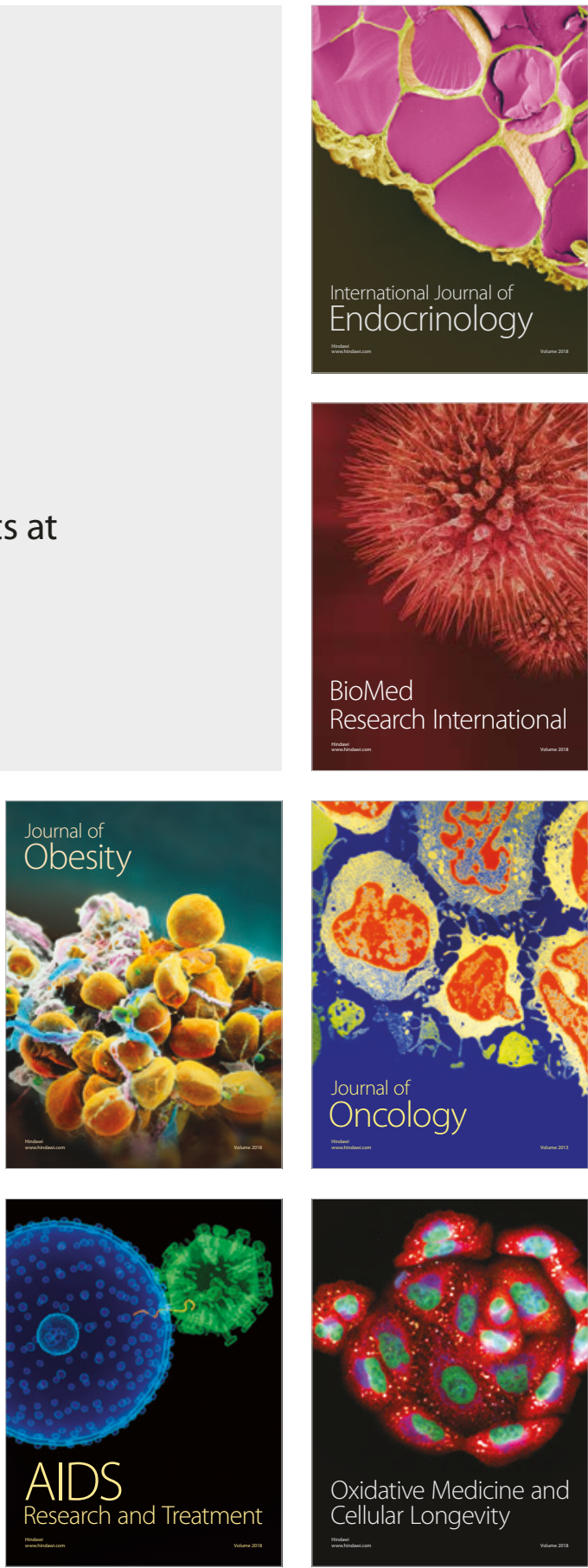